The intervention group will receive tailored work-related support consisting of three face-to-face meetings. Based on the severity of their work-related problems, the intervention group will be divided into groups receiving three types of support (A, B or C). A different supportive healthcare professional will be available for each group: an oncological nurse (A), an oncological occupational physician (B) and a multidisciplinary team (C) that includes an oncological nurse, oncological occupational physician and treating oncologist/physician.

Result The work-related support intervention including vocational counselling and discussion of legal issues and diseaserelated and treatment-related factors that may affect work. Primary outcome measure is return to work (RTW), defined as the time to a partial or full RTW. Secondary outcomes are work ability, work limitations, quality of life, and direct and indirect costs. Outcomes are assessed with patient questionnaires at baseline and 3, 6, 9, and 12 months follow up.

Discussion The hypothesis is that tailored work-related support for GI cancer patients is more effective than usual care on RTW. The intervention is innovative in that it combines oncological and occupational care in a clinical setting, early in the cancer treatment process.

This study will contribute as a foundation for optimising future tailored work- related interventions in cancer care with the intention to implement the intervention if it has been shown effective.

\section{DEVELOPING A COMMUNICATION TOOL TO PROMOTE DISCUSSION AMONG STAKEHOLDERS IN WORK DISABILITY: A COLLABORATIVE APPROACH}

MF Coutu*, MJ Durand, The Mist-Caprit Team. Université de Sherbrooke, Longueuil, Quebec, Canada

\subsection{6/oemed-2018-ICOHabstracts. 1582}

Introduction The involvement of stakeholders from outside academia is key to producing sustainability science. Several challenges need to be addressed in the development of a partnership between research and practice. Many stakeholders from different social systems are involved in disability management practice. They may not share the same understanding of the issues and solutions at stake, causing unbalanced problem ownership within the group. To help reduce this barrier, we sought to build a tool that would establish a common vocabulary between researchers and stakeholders.

Methods A multimethod approach was used. A set of definitions for key terms was developed with an advisory committee (researchers and stakeholders). A Web-based survey with closed and open questions was then used to assess the level of agreement with, first, the inclusion of these terms and then with their definitions. Terms whose inclusion had more than $70 \%$ agreement were retained. In cases of disagreement with a definition, participants suggested modifications. Terms whose definitions had less than $70 \%$ agreement were discussed in the next phase. Finally, a series of group consensus meetings were conducted to discuss the suggested modifications emerging from the survey and to determine the final definitions of the terms.

Results A total of 8 multidisciplinary researchers, 2 postdoctoral students, and 12 stakeholders representing patients, employers, unions, healthcare professionals, and legal and insurance systems completed the survey and participated in the consensus groups. A consensus for inclusion $(\geq 70 \%$ of agreement) was reached for all 79 initially proposed terms. Of the 79 terms, 20 needed clarification ( $\leq 70 \%$ of agreement). These were discussed in three consensus group meetings. At the end, a final version of the definitions of all 79 terms was produced.

Discussion This multimethod approach ensures the use of the same reference points, regardless of participants' different concerns.

\section{USING MOBILE TECHNOLOGY TO SUPPORT VOCATIONAL TRAINING FOR ADOLESCENTS WITH LEARNING DIFFICULTIES: A PILOT STUDY}

${ }^{1,2,3} \mathrm{M}$ Laberge* ${ }^{2} \mathrm{~A}$ Tondoux, ${ }^{2} \mathrm{~A}$ Blanchard, ${ }^{1,2} \mathrm{~F}$ Camiré Tremblay, ${ }^{1,2} \mathrm{MM}$ Girard. ${ }^{1}$ University of Montreal, Montreal, Canada; ${ }^{2} \mathrm{CHU}$ Ste-Justine research Centre, Montreal, Canada; ${ }^{3}$ CINBIOSE research Centre, Montreal, Canada

\subsection{6/oemed-2018-ICOHabstracts. 1583}

Introduction Adolescents with learning difficulties are at risk of leaving school without a qualifying certification. They may experience difficulties in entering the labour market. In Quebec (Canada), the Work-Oriented Training Path (WOTP) enables these young people to develop their employability by offering pre-work traineeships in actual companies. The aim of this pilot study was to develop an innovative intervention based on using technological aids to help students enrolled in the WOTP programs developing work skills.

Methods Eight teachers and fifteen students enrolled in the WOTP participated in a multiple case study. Teachers first attended a training workshop and were then asked to apply a method to conduct workplace analysis and technological aid allocation for two students. They were free to choose any applications. Each two months, a collective meeting was organised to share the various experimentations; the content of meetings was recorded and analysed. Additional data was collected along the study (log book, questionnaires, interviews). Data triangulation led to a portrait of utilisation barriers and facilitators. Findings were used to establish specifications for future intervention.

Results According to teachers, the principal needs of their students are related to spatial and temporal organisation, execution speed, motor skills, communication difficulties, and learning transfer in various contexts. Teachers mostly used simple, usual and free apps, like calendar, notes, alarm functions, checklists, and few more complex apps that required programming, as My video coach, Shadow Puppet, Explain Everything. The main difficulties with technological aids encountered by teachers concerned the relationship with traineeship companies, implementation time and the degree of involvement of students.

Discussion Two principal stakes emerged from this study. If they are to be used in workplaces, technologies must (1) be operative (i.e. useable and useful at the moment required), and (2) be used autonomously by students in workplace for subsequent mobilisation. 